OPEN ACCESS

Edited by:

Greg Stuart

Australian National University,

Australia

Reviewed by:

Jeffrey C. Erlich,

New York University Shanghai, China

Lukas lan Schmitt, Massachusetts Institute of Technology, United States

*Correspondence: Sophia Bakola sofia.bakola@monash.edu Yan T. Wong yan.wong@monash.edu

tThese authors have contributed equally to this work

Received: 26 September 2018 Accepted: 21 February 2019 Published: 11 March 2019

Citation: Hadjidimitrakis K, Bakola S, Wong YT and Hagan MA (2019) Mixed Spatial and Movement Representations in the Primate Posterior Parietal Cortex. Front. Neural Circuits 13:15. doi: 10.3389/fncir.2019.00015

\section{Mixed Spatial and Movement Representations in the Primate Posterior Parietal Cortex}

\author{
Kostas Hadjidimitrakis $^{1,2 \dagger}{ }^{\text {, Sophia Bakola }}{ }^{1,2 * \dagger}$, Yan T. Wong ${ }^{1,3 * \dagger}$ and Maureen A. Hagan ${ }^{1,2 \dagger}$ \\ ${ }^{1}$ Department of Physiology, Monash University, Clayton, VIC, Australia, ${ }^{2}$ Australian Research Council Centre of Excellence for \\ Integrative Brain Function, Monash University Node, Clayton, VIC, Australia, ${ }^{3}$ Department of Electrical and Computer Science \\ Engineering, Monash University, Clayton, VIC, Australia
}

The posterior parietal cortex (PPC) of humans and non-human primates plays a key role in the sensory and motor transformations required to guide motor actions to objects of interest in the environment. Despite decades of research, the anatomical and functional organization of this region is still a matter of contention. It is generally accepted that specialized parietal subregions and their functional counterparts in the frontal cortex participate in distinct segregated networks related to eye, arm and hand movements. However, experimental evidence obtained primarily from single neuron recording studies in non-human primates has demonstrated a rich mixing of signals processed by parietal neurons, calling into question ideas for a strict functional specialization. Here, we present a brief account of this line of research together with the basic trends in the anatomical connectivity patterns of the parietal subregions. We review, the evidence related to the functional communication between subregions of the PPC and describe progress towards using parietal neuron activity in neuroprosthetic applications. Recent literature suggests a role for the PPC not as a constellation of specialized functional subdomains, but as a dynamic network of sensorimotor loci that combine multiple signals and work in concert to guide motor behavior.

Keywords: eye movements, reaching, grasping, PPC, posterior parietal cortex, movement planning

\section{INTRODUCTION}

Humans and non-human primates make skillful reaching-to-grasping movements that are tightly coordinated in space and time (Jeannerod et al., 1995). Moreover, eye movements often accompany every day actions towards objects, supplying information about object identity and location, and guiding arm movements (Johansson et al., 2001; Land and Hayhoe, 2001; Hayhoe et al., 2003). Contemporary research has established that the posterior parietal cortex (PPC) is involved in the representation of spatial information and goal-directed behavior using different motor effectors (Husain and Nachev, 2007; Andersen and Cui, 2009). Since the original unified view of PPC as a "command apparatus for the operation of the limbs, hands and eyes" (Mountcastle et al., 1975), anatomical, neurophysiological and neuroimaging evidence has ascribed the neural encoding of looking, reaching and grasping actions to distinct PPC sectors (Rizzolatti and Matelli, 2003; Vesia and Crawford, 2012; Andersen et al., 2014).

At the same time, numerous studies have shown convergence of eye-, arm- and/or hand-related signals, both within single PPC sectors and at the level of individual cells, although which of these signals play a casual role in defining functional specificity would require future investigations. Recent research findings raise several issues regarding the potential substrates of distinct 
movements in parietal cortex and the information flow between the various PPC sectors. Here, we outline evidence, mainly from non-human primate anatomical and neurophysiological studies, for the rich variety of signals carried by PPC neurons related to movement guidance that suggests a more widespread representation of movement variables than previously assumed. From a clinical perspective, the diverse representation of signals from parietal cortex may prove useful for the design of more efficient neuroprosthetic devices for patients who cannot reach and grasp objects either because of loss of arms or lesions of the motor pathways.

\section{ANATOMICAL ORGANIZATION OF THE POSTERIOR PARIETAL CORTEX}

The PPC is composed of several areas that vary in histological features and connections with other parts of the brain. Definitions of areas have evolved over time from the historical assignment of posterior parietal fields to areas 5 and 7 of Brodmann to more refined schemes (e.g., Figure 1) but, despite general consensus on the number and characteristics of individual areas, maps produced by different groups vary widely and functional subdivisions do not always appear to respect architectonic boundaries (e.g., Savaki et al., 2010; Arcaro et al., 2011; Seelke et al., 2012). Nonetheless, in non-human primates, the anatomical organization of PPC is shaped by the relative influence of sensorimotor input to different areas. Segregated projections from the motor control centers in the frontal lobe are distributed along the dorsal-ventral extent of PPC. Primary motor cortex connects mainly to the parietal convexity (PE) and rostral parts of the medial bank of the intraparietal sulcus (IPS; PEip). Caudal superior and medial parietal areas (V6A, MIP, PEc, 31) connect preferentially with parts of dorsal premotor cortex, whereas inferior parietal areas (PFG, PF, AIP, VIP) connect with the ventral premotor cortex (Marconi et al., 2001; Tanné-Gariépy et al., 2002; Rozzi et al., 2006; Borra et al., 2008; Gamberini et al., 2009; Bakola et al., 2010, 2017; Passarelli et al., 2011, 2018). Input to LIP (Blatt et al., 1990; Lewis and Van Essen, 2000) and PGm (Cavada and Goldman-Rakic, 1989; Passarelli et al., 2018) originates mainly in the oculomotor-related frontal eye fields (FEFs). Segregation of motor projections is not in absolute terms, though, since each parietal area usually receives convergent input from other structures; e.g., PEip receives additional projections from ventral premotor cortex (Tanné-Gariépy et al., 2002; Bakola et al., 2017).

A relative segregation of sensory-specific projections has been described along the rostral-caudal dimension, with somaticrelated input targeting heavily rostral parietal areas (Rozzi et al., 2006; Bakola et al., 2013; Padberg et al., 2019). Visual inputs (in particular representations of peripheral vision) are prominent in caudal parietal areas, however there is variation in the source of visual afferents to PPC. For example, numerous afferents to V6A (Passarelli et al., 2011) and LIP (Lewis and Van Essen, 2000) originate in area $\mathrm{V} 6$, whereas caudal inferior parietal lobe receives almost exclusively projections from the motion area MST of the temporal cortex (Rozzi et al., 2006). Several projections to MIP and PGm arrive also from the putative visual region

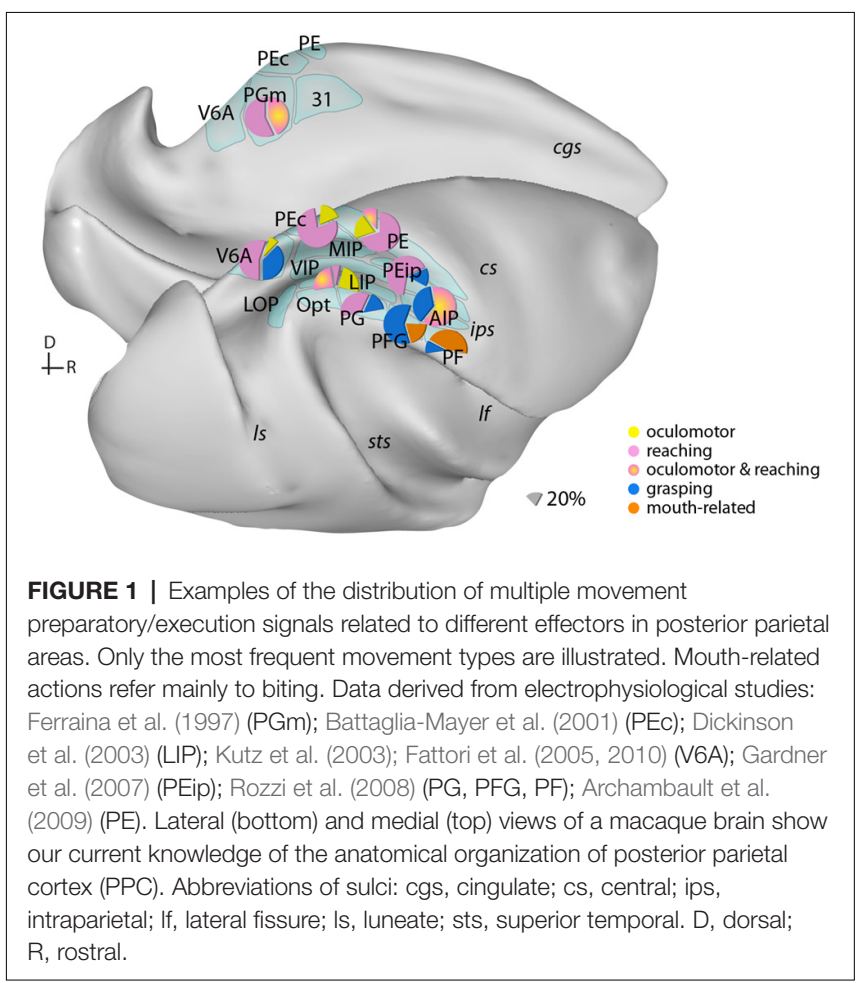

(Kobayashi and Amaral, 2003), ventral to PGm (Bakola et al., 2017; Passarelli et al., 2018). In addition to sensorimotor input, PPC receives segregated input from other systems. For example, caudal/medial areas receive projections from limbic fields of the brain (Rozzi et al., 2006; Bakola et al., 2017; Passarelli et al., 2018). These include projections from the posterior cingulate and retrosplenial regions and area prostriata (Yu et al., 2012) and likely represent routes by which information about spatial orientation and memory reaches parts of PPC (Vann et al., 2009; Kravitz et al., 2011).

Despite the diversity of extrinsic connections, short-range intrinsic connections between adjacent parietal areas form a substantial component of areal connectivity, highlighting the potentially large influence of local processing in defining the function of PPC sectors (Caminiti et al., 2017). This organization may support synergistic actions of different effectors to produce meaningful movements (Kaas and Stepniewska, 2016; Catani et al., 2017).

\section{FUNCTIONAL RESPONSE PROPERTIES IN INDIVIDUAL REGIONS OF THE POSTERIOR PARIETAL CORTEX}

Two exemplar nodes of the functional specialization view on PPC are areas AIP and LIP that have been associated with the control of hand-object interactions required for grasping and for the guidance of eye movements, respectively (Gallese et al., 1994; Andersen et al., 1998; Murata et al., 2000; Cui and Andersen, 2007). By comparison, planning and execution of reaching movements appear to be distributed in several areas of the superior (V6A, PEc, MIP and PE/PEip) and inferior parietal 
lobe (Snyder et al., 1997; Battaglia-Mayer et al., 2000, 2007; Fattori et al., 2005; Heider et al., 2010; McGuire and Sabes, 2011; Hadjidimitrakis et al., 2012, 2015).

Influential models for parallel parietal-frontal networks for motor actions have dominated parietal research in the past (Jeannerod et al., 1995; Matelli and Luppino, 2001). Accordingly, reach-related signals flow from the superior parietal to the dorsal premotor cortex and grasp-related activity is conveyed from AIP to ventral premotor cortex; both streams converge to the primary motor cortex (Burman et al., 2014; Dea et al., 2016). Re-evaluation of these models became necessary after studies showing that individual premotor neurons carried both reaching and grasping information (Raos et al., 2004; Stark et al., 2007). Along these lines, later work reported grasping parameters to be coded in the traditionally reaching domains of the superior parietal cortex (Chen et al., 2009; Fattori et al., 2010). Furthermore, single AIP neurons encoded both the reaching direction and grip type (Lehmann and Scherberger, 2013).

Additional evidence for the mixing of neural signals comes from work on the spatial reference frames used for reaching movements. Until recently, the dominant view was that neurons in each parietal area have uniform reference frames. A serial organization of reach-related responses along the extent of PPC has been reported, with responses coding target locations relative to the eyes (eye-centered frame) recorded caudally and responses coding locations in head-, body- and hand-centered frame rostrally (Flanders et al., 1992). This view found support in studies that showed eye-centered reference frames caudally in the parietal reach region (PRR, Snyder et al., 1997) and hand-centered representations rostrally in area PE (Lacquaniti et al., 1995; Batista et al., 1999; Buneo et al., 2002; Marzocchi et al., 2008). However, later work showed that neurons in single PPC areas encode reaches relative to the eye, hand, head and body (Mullette-Gillman et al., 2009; Chang and Snyder, 2010; McGuire and Sabes, 2011; Hadjidimitrakis et al., 2014b; Bosco et al., 2016; Piserchia et al., 2017). The presence of mixed, eyeand limb-centered, reference frames within several PPC areas challenges the one-to-one association of a particular type of reference frame with one region and, subsequently, the view of serial reference frame transformations across the PPC "reach" network (McGuire and Sabes, 2011).

Mixing of signals has also been observed at another level of movement control. The distance and direction of reach goals, which were considered to have independent neuronal substrates (Crawford et al., 2011), were encoded by largely overlapping neuronal populations in V6A and PEc (Hadjidimitrakis et al., 2014a, 2015; Filippini et al., 2018). Furthermore, PRR neurons can simultaneously encode multiple potential movement goals (Baldauf et al., 2008; Klaes et al., 2011), thus further illustrating the richness of the selectivity.

In a recent human study, Zhang et al. (2017) reported a mixture of effector representations in populations of neurons in the putative homolog of macaque AIP, arguing against a strict anatomical segregation of body parts. Using fMRI repetition suppression, Heed et al. (2016) examined activity in the PPC in humans performing delayed eye, hand and foot movements to visual targets. They reported a gradient of organization schemes along the extent of PPC, with a region activated independently of the effector used among regions showing effector specificity. Accordingly, the view that emerges is that the primate PPC hosts multiple representations of motor actions, with individual areas and networks (e.g., reaching network) showing only a relative emphasis on a particular effector or movement type.

\section{A POTENTIAL NETWORK FOR EYE-ARM COORDINATION}

The mixed selectivity and overlapping representations for different movements in PPC make it an ideal site for mediating complex behaviors like eye-hand coordination. Indeed, growing evidence suggests that coordinated behaviors, such as eye-hand movements, rely on parietal circuits. Reaction times for eye and hand movements are correlated (Dean et al., 2011), suggesting a common neural mechanism. The mixing of various types of signals in single PPC neurons and sectors could be interpreted as a manifestation of coordinated activity. For example, most LIP neurons fire stronger when a combined reach and saccade is planned compared to a saccade alone (Hagan et al., 2012). Neural correlates for single and combined eye- and arm-related movements were reported in several PPC fields (Battaglia-Mayer et al., 2001; Calton et al., 2002; Dickinson et al., 2003), with activity being usually weaker for the non-preferred movement. Moreover, neural responses are modulated by static eye and arm position in $\mathrm{PEc}, \mathrm{V} 6 \mathrm{~A}$ and the caudal inferior parietal lobe (Battaglia-Mayer et al., 2000, 2007; Breveglieri et al., 2012, 2014; Piserchia et al., 2017).

The mixing of signals within PPC may result from the short-range intrinsic connections between adjacent parietal areas (Caminiti et al., 2017). In order to understand the mixed selectivity and how it relates to complex behaviors, simultaneous recordings from multiple PPC areas are necessary. However, very few works have employed this method in PPC (e.g., Cui and Andersen, 2007; Dean et al., 2012). By comparison, increasingly interactions between areas of the frontal and parietal cortex are being studied. Multi-area recordings in primates allow for correlations between the activity across areas to be studied and have complemented non-invasive work using fMRI and MEG.

In electrophysiological studies, the local field potential (LFP) has been instrumental in understanding the relationship in neural activity across brain areas. The LFP is composed of synaptic and spiking activity in the vicinity of the recording electrode (Mitzdorf, 1985), and gives an estimate of the population activity. Like spiking-activity, the LFP power is tuned to saccade and reach direction in LIP and PRR, respectively (Pesaran et al., 2002; Scherberger et al., 2005). Synchrony, or coherence, between the firing rates of individual neurons and the LFP at different frequencies may reflect the processing of different types of information (Fries, 2005). During coordinated eye-hand movements, the beta-band ( $\sim 15-30 \mathrm{~Hz})$ LFP activity decreases around movement initiation in both LIP and PRR, and correlates with the reaction times for coordinated reach and saccades (but not for saccades made alone, Dean et al., 2012). Furthermore, LIP neurons with reduced activity during eye-hand 
movements, compared to saccades, tend to be coherent with the beta-band LFP (Hagan et al., 2012) and their firing rate predicts the reaction times of coordinated eye-hand movements. This suggests that these neurons participate in a neural circuit that orchestrates coordinated eye-hand movements (Dean et al., 2012). Coherent activity across areas may also contribute to the processing of cognitive signals such as decision-making (Hawellek et al., 2016; Wong et al., 2016) and visual attention in PPC (Buschman and Miller, 2007; Saalmann et al., 2007; Gregoriou et al., 2009).

The studies of LFP-firing coherence are limited in their ability to provide causal evidence of the role of the PPC in eye-hand coordination. In this regard, a number of inactivation studies in PPC have provided more direct evidence, with two works reporting effects on limb (but not eye) movements (Hwang et al., 2012; Yttri et al., 2014), whereas another one found disrupted eye-hand correlations after bilateral inactivation (BattagliaMayer et al., 2013). Furthermore, unilateral inactivation of LIP combined with fMRI resulted in rapid spatial reorganization in the active hemisphere (Wilke et al., 2012), suggesting that the functions of PPC are likely spread over a wider network that extends over both hemispheres. This could also explain recent evidence showing no effect of unilateral LIP inactivation on decision-making (Katz et al., 2016). Similarly, inactivation of VIP had no effect on behavior in a heading discrimination task (Chen et al., 2016). In humans, fMRI-guided transcranial magnetic stimulation demonstrated a causal role of the anterior portion of the IPS to reaching (Reichenbach et al., 2011). Overall, inactivation evidence should be treated cautiously. More sensitive activity manipulations could be useful to determine how PPC nodes contribute to motor behaviors. The use of sophisticated tools such as optogenetics in primates (Jazayeri et al., 2012; Watakabe et al., 2016; El-Shamayleh et al., 2017) could help overcome current limitations.

\section{IMPLICATIONS OF MIXED SELECTIVITY IN THE PPC FOR MEDICAL INTERVENTIONS}

The diversity of signals within the PPC has sparked great interest to the neuroprosthetic community. For patients suffering from loss of function due to paralysis or amputation of a limb, there can be great difficulty in interacting with people or everyday objects. Brain machine interfaces (BMIs) offer some hope in helping remedy these difficulties. A BMI is a device that can record neural activity from the brain while subjects think about a certain task, and then via a decoder, extract the subject's intentions. These decoded intentions are used to control external devices that can vary from a cursor on a monitor, to an anthromorphic robotic arm and hand, to a functional electrical stimulator to activate paralyzed muscles.

Most commonly, electrodes are implanted in the primary motor and premotor areas while patients use motor imagery to provide the necessary input to these BMIs (Markowitz et al., 2011; Hochberg et al., 2012; Collinger et al., 2013). Devices implanted in the motor areas typically decode the trajectory of an effector. Early studies showed that PPC neurons could be used in conjunction with frontal motor areas to control closed loop BMIs, however it was unclear to what extent the PPC neurons contributed to the efficacy of these devices (Wessberg et al., 2000). In a study that compared offline decoding of hand position and velocity in non-human primates, decoding with PPC neurons was inferior to the decoding performance achieved with primary motor and dorsal premotor cortex (Carmena et al., 2003), possibly indicating that the PPC neurons were not contributing much to the overall control.

However, Musallam et al. (2004) went on to demonstrate that high level movement goal information as well as expected reward values of different targets could be decoded from signals in PRR to control a cursor on the screen during a BMI task. These control signals could be generated in the absence of an actual movement. The goal signals allow an abstraction away from the low-level commands necessary to achieve the wanted action as well as the device that actually enacts the action. These low-level commands can be generated through external optimal control algorithms. Goals for multiple sequential movements are planned in PRR (Baldauf et al., 2008) but not in the superior parietal convexity (Li and Cui, 2013) providing a rich mix of signals.

However, soon after this, trajectory information was successfully decoded from the medial bank of the IPS as well as the dorsal convexity to allow control of a 2-dimensional (2D; Mulliken et al., 2008a,b) as well as 3D (Hauschild et al., 2012) cursor on a screen. Decoding algorithms to incorporate the cognitive neural signals and the trajectory information will also provide increased performance compared to each type of signal alone (Shanechi et al., 2013a,b). These studies primarily focused on decoding of spiking activity, but similar information could be extracted from the LFP (Andersen et al., 2004; Scherberger et al., 2005).

The clinical relevance of the PPC to neural prosthetics was demonstrated in the first human trial of a BMI that utilized neural signals from the PPC (Aflalo et al., 2015). In this study, a tetraplegic patient was implanted with electrode arrays in putative areas $5 \mathrm{~d} / \mathrm{PE}$ and AIP and could successfully control $2 \mathrm{D}$ and $3 \mathrm{D}$ cursors as well as a robotic limb. Therefore, exploiting the richness of information in the PPC may be an advantageous strategy for developing more efficient BMIs.

\section{CONCLUDING REMARKS}

Despite decades of research, a definitive understanding of how individual brains areas are defined, perform distinct computations, and interact with other brain areas remains elusive. The PPC has proved an ideal test bed for understanding how the underlying neural architecture supports a range of sensory, motor and cognitive functions. Anatomy and physiology provide distinct lines of evidence for characterizing the brain areas of the PPC less as a cluster of finite regions and more as a network of integrated areas that may flexibly form the neural basis for diverse functions. The future of systems neuroscience is in understanding how these brain areas work in concert with one another and how the neural dynamics can be used for powering the next generation of prosthetic devices. 


\section{AUTHOR CONTRIBUTIONS}

$\mathrm{KH}, \mathrm{SB}, \mathrm{YW}$ and $\mathrm{MH}$ contributed to the preparation, writing and revising of this text.

\section{FUNDING}

We acknowledge the Australian Research Council (DE120102883, DE180100344), National Health and Medical

\section{REFERENCES}

Aflalo, T., Kellis, S., Klaes, C., Lee, B., Shi, Y., Pejsa, K., et al. (2015). Decoding motor imagery from the posterior parietal cortex of a tetraplegic human. Science 348, 906-910. doi: 10.1126/science.aaa5417

Andersen, R. A., Andersen, K. N., Hwang, E. J., and Hauschild, M. (2014). Optic ataxia: from Balint's syndrome to the parietal reach region. Neuron 81, 967-983. doi: 10.1016/j.neuron.2014.02.025

Andersen, R. A., and Cui, H. (2009). Intention, action planning, and decision making in parietal-frontal circuits. Neuron 63, 568-583. doi: 10.1016/j.neuron. 2009.08.028

Andersen, R. A., Musallam, S., and Pesaran, B. (2004). Selecting the signals for a brain-machine interface. Curr. Opin. Neurobiol. 14, 720-726. doi: 10.1016/j. conb.2004.10.005

Andersen, R. A., Snyder, L. H., Batista, A. P., Buneo, C. A., and Cohen, Y. E. (1998). Posterior parietal areas specialized for eye movements (LIP) and reach (PRR) using a common coordinate frame. Novartis Found. Symp. 218, 109-122; discussion 122-128, 171-175. doi: 10.1002/9780470515563.ch7

Arcaro, M. J., Pinsk, M. A., Li, X., and Kastner, S. (2011). Visuotopic organization of macaque posterior parietal cortex: a functional magnetic resonance imaging study. J. Neurosci. 31, 2064-2078. doi: 10.1523/JNEUROSCI.3334-10.2011

Archambault, P. S., Caminiti, R., and Battaglia-Mayer, A. (2009). Cortical mechanisms for online control of hand movement trajectory: the role of the posterior parietal cortex. Cereb. Cortex 19, 2848-2864. doi: 10.1093/cercor/bhp058

Bakola, S., Gamberini, M., Passarelli, L., Fattori, P., and Galletti, C. (2010). Cortical connections of parietal field PEc in the macaque: linking vision and somatic sensation for the control of limb action. Cereb. Cortex 20, 2592-2604. doi: 10.1093/cercor/bhq007

Bakola, S., Passarelli, L., Gamberini, M., Fattori, P., and Galletti, C. (2013). Cortical connectivity suggests a role in limb coordination for macaque area PE of the superior parietal cortex. J. Neurosci. 33, 6648-6658. doi: 10.1523/JNEUROSCI. 4685-12.2013

Bakola, S., Passarelli, L., Huynh, T., Impieri, D., Worthy, K. H., Fattori, P., et al. (2017). Cortical afferents and myeloarchitecture distinguish the medial intraparietal area (MIP) from neighboring subdivisions of the macaque cortex. eNeuro 4:ENEURO.0344-17.2017. doi: 10.1523/eneuro.034417.2017

Baldauf, D., Cui, H., and Andersen, R. A. (2008). The posterior parietal cortex encodes in parallel both goals for double-reach sequences. J. Neurosci. 28, 10081-10089. doi: 10.1523/JNEUROSCI.3423-08.2008

Batista, A. P., Buneo, C. A., Snyder, L. H., and Andersen, R. A. (1999). Reach plans in eye-centered coordinates. Science 285, 257-260. doi: 10.1126/science. 285.5425.257

Battaglia-Mayer, A., Ferraina, S., Genovesio, A., Marconi, B., Squatrito, S., Molinari, M., et al. (2001). Eye-hand coordination during reaching. II. An analysis of the relationships between visuomanual signals in parietal cortex and parieto-frontal association projections. Cereb. Cortex 11, 528-544. doi: 10.1093/cercor/11.6.528

Battaglia-Mayer, A., Ferraina, S., Mitsuda, T., Marconi, B., Genovesio, A., Onorati, P., et al. (2000). Early coding or reaching in the parietooccipital cortex. J. Neurophysiol. 83, 2374-2391. doi: 10.1152/jn.2000.83.4.2374

Battaglia-Mayer, A., Ferrari-Toniolo, S., Visco-Comandini, F., Archambault, P. S., Saberi-Moghadam, S., and Caminiti, R. (2013). Impairment of online control of hand andD eye movements in a monkey model of optic ataxia. Cereb. Cortex 23, 2644-2656. doi: 10.1093/cercor/bhs250
Research Council (1020839, 1082144), H2020-MSCA-734227PLATYPUS and EU Fellowship FP7-PEOPLE-2011-IOF 300452 (SB) for financial support.

\section{ACKNOWLEDGMENTS}

We thank Marcello Rosa and Patrizia Fattori for helpful discussions and support.

Battaglia-Mayer, A., Mascaro, M., and Caminiti, R. (2007). Temporal evolution and strength of neural activity in parietal cortex during eye and hand movements. Cereb. Cortex 17, 1350-1363. doi: 10.1093/cercor/bhl046

Blatt, G. J., Andersen, R. A., and Stoner, G. R. (1990). Visual receptive field organization and cortico-cortical connections of the lateral intraparietal area (area LIP) in the macaque. J. Comp. Neurol. 299, 421-445. doi: 10.1002/cne. 902990404

Borra, E., Belmalih, A., Calzavara, R., Gerbella, M., Murata, A., Rozzi, S., et al. (2008). Cortical connections of the macaque anterior intraparietal (AIP) area. Cereb. Cortex 18, 1094-1111. doi: 10.1093/cercor/bhm146

Bosco, A., Breveglieri, R., Hadjidimitrakis, K., Galletti, C., and Fattori, P. (2016). Reference frames for reaching when decoupling eye and target position in depth and direction. Sci. Rep. 6:21646. doi: 10.1038/srep21646

Breveglieri, R., Galletti, C., Dal Bò, G., Hadjidimitrakis, K., and Fattori, P. (2014). Multiple aspects of neural activity during reaching preparation in the medial posterior parietal area V6A. J. Cogn. Neurosci. 26, 878-895. doi: 10.1162/jocn_a_00510

Breveglieri, R., Hadjidimitrakis, K., Bosco, A., Sabatini, S. P., Galletti, C., and Fattori, P. (2012). Eye position encoding in three-dimensional space: integration of version and vergence signals in the medial posterior parietal cortex. J. Neurosci. 32, 159-169. doi: 10.1523/JNEUROSCI.402811.2012

Buneo, C. A., Jarvis, M. R., Batista, A. P., and Andersen, R. A. (2002). Direct visuomotor transformations for reaching. Nature 416, 632-636. doi: $10.1038 / 416632 a$

Burman, K. J., Bakola, S., Richardson, K. E., Reser, D. H., and Rosa, M. G. P. (2014). Patterns of cortical input to the primary motor area in the marmoset monkey. J. Comp. Neurol. 522, 811-843. doi: 10.1002/cne.23447

Buschman, T. J., and Miller, E. K. (2007). Top-down versus bottom-up control of attention in the prefrontal and posterior parietal cortices. Science 315, 1860-1862. doi: 10.1126/science.1138071

Calton, J. L., Dickinson, A. R., and Snyder, L. H. (2002). Non-spatial, motorspecific activation in posterior parietal cortex. Nat. Neurosci. 5, 580-588. doi: 10.1038/nn0602-862

Caminiti, R., Borra, E., Visco-Comandini, F., Battaglia-Mayer, A., Averbeck, B. B., and Luppino, G. (2017). Computational architecture of the parietofrontal network underlying cognitive-motor control in monkeys. eNeuro 4:ENEURO.0306-16.2017. doi: 10.1523/eneuro.0306-16.2017

Carmena, J. M., Lebedev, M. A., Crist, R. E., O’Doherty, J. E., Santucci, D. M. Dimitrov, D. F., et al. (2003). Learning to control a brain-machine interface for reaching and grasping by primates. PLoS Biol. 1:e42. doi: 10.1371/journal.pbio. 0000042

Catani, M., Robertsson, N., Beyh, A., Huynh, V., de Santiago Requejo, F., Howells, H., et al. (2017). Short parietal lobe connections of the human and monkey brain. Cortex 97, 339-357. doi: 10.1016/j.cortex.2017.10.022

Cavada, C., and Goldman-Rakic, P. S. (1989). Posterior parietal cortex in rhesus monkey: II. Evidence for segregated corticocortical networks linking sensory and limbic areas with the frontal lobe. J. Comp. Neurol. 287, 422-445. doi: $10.1002 /$ cne. 902870403

Chang, S. W. C., and Snyder, L. H. (2010). Idiosyncratic and systematic aspects of spatial representations in the macaque parietal cortex. Proc. Natl. Acad. Sci. U S A 107, 7951-7956. doi: 10.1073/pnas.0913209107

Chen, A., Gu, Y., Liu, S., DeAngelis, G. C., and Angelaki, D. E. (2016). Evidence for a causal contribution of macaque vestibular, but not intraparietal, cortex to heading perception. J. Neurosci. 36, 3789-3798. doi: 10.1523/JNEUROSCI. 2485-15.2016 
Chen, J., Reitzen, S. D., Kohlenstein, J. B., and Gardner, E. P. (2009). Neural representation of hand kinematics during prehension in posterior parietal cortex of the macaque monkey. J. Neurophysiol. 102, 3310-3328. doi: 10.1152/jn.90942.2008

Collinger, J. L., Wodlinger, B., Downey, J. E., Wang, W., Tyler-Kabara, E. C., Weber, D. J., et al. (2013). High-performance neuroprosthetic control by an individual with tetraplegia. Lancet 381, 557-564. doi: 10.1016/S01406736(12)61816-9

Crawford, J. D., Henriques, D. Y., and Medendorp, W. P. (2011). Threedimensional transformations for goal-directed action. Annu. Rev. Neurosci. 34, 309-331. doi: 10.1146/annurev-neuro-061010-113749

Cui, H., and Andersen, R. A. (2007). Posterior parietal cortex encodes autonomously selected motor plans. Neuron 56, 552-559. doi: 10.1016/j. neuron.2007.09.031

Dea, M., Hamadjida, A., Elgbeili, G., Quessy, S., and Dancause, N. (2016). Different patterns of cortical inputs to subregions of the primary motor cortex hand representation in cebus apella. Cereb. Cortex 26, 1747-1761. doi: 10.1093/cercor/bhv324

Dean, H. L., Hagan, M. A., and Pesaran, B. (2012). Only coherent spiking in posterior parietal cortex coordinates looking and reaching. Neuron 73, 829-841. doi: 10.1016/j.neuron.2011.12.035

Dean, H. L., Martí, D., Tsui, E., Rinzel, J., and Pesaran, B. (2011). Reaction time correlations during eye-hand coordination: behavior and modeling. J. Neurosci. 31, 2399-2412. doi: 10.1523/JNEUROSCI.4591-10.2011

Dickinson, A. R., Calton, J. L., and Snyder, L. H. (2003). Nonspatial saccadespecific activation in area LIP of monkey parietal cortex. J. Neurophysiol. 90, 2460-2464. doi: 10.1152/jn.00788.2002

El-Shamayleh, Y., Kojima, Y., Soetedjo, R., and Horwitz, G. D. (2017). Selective optogenetic control of purkinje cells in monkey cerebellum. Neuron 95, 51.e4-62.e4. doi: 10.1016/j.neuron.2017.06.002

Fattori, P., Kutz, D. F., Breveglieri, R., Marzocchi, N., and Galletti, C. (2005). Spatial tuning of reaching activity in the medial parieto-occipital cortex (area V6A) of macaque monkey. Eur. J. Neurosci. 22, 956-972. doi: 10.1111/j.14609568.2005.04288.x

Fattori, P., Raos, V., Breveglieri, R., Bosco, A., Marzocchi, N., and Galletti, C. (2010). The dorsomedial pathway is not just for reaching: grasping neurons in the medial parieto-occipital cortex of the macaque monkey. J. Neurosci. 30, 342-349. doi: 10.1523/JNEUROSCI.3800-09.2010

Ferraina, S., Garasto, M. R., Battaglia-Mayer, A., Ferraresi, P., Johnson, P. B., Lacquaniti, F., et al. (1997). Visual control of hand reaching movement: activity in parietal area 7m. Eur. J. Neurosci. 9, 1090-1095. doi: 10.1111/j.1460-9568. 1997.tb01460.x

Filippini, M., Breveglieri, R., Hadjidimitrakis, K., Bosco, A., and Fattori, P. (2018). Prediction of reach goals in depth and direction from the parietal cortex. Cell Rep. 23, 725-732. doi: 10.1016/j.celrep.2018.03.090

Flanders, M., Helms Tillery, S. I., and Soechting, J. F. (1992). Early stages in a sensorimotor transformation. Behav. Brain Sci. 15, 309-362. doi: $10.1017 / \mathrm{s} 0140525 \times 00068813$

Fries, P. (2005). A mechanism for cognitive dynamics: neuronal communication through neuronal coherence. Trends Cogn. Sci. 9, 474-480. doi: 10.1016/j.tics. 2005.08.011

Gallese, V., Murata, A., Kaseda, M., Niki, N., and Sakata, H. (1994). Deficit of hand preshaping after muscimol injection in monkey parietal cortex. Neuroreport 5, 1525-1529. doi: 10.1097/00001756-199407000-00029

Gamberini, M., Passarelli, L., Fattori, P., Zucchelli, M., Bakola, S., Luppino, G., et al. (2009). Cortical connections of the visuomotor parietooccipital area V6Ad of the macaque monkey. J. Comp. Neurol. 513, 622-642. doi: 10.1002/cne.21980

Gardner, E. P., Babu, K. S., Reitzen, S. D., Ghosh, S., Brown, A. S., Chen, J., et al. (2007). Neurophysiology of prehension. I. Posterior parietal cortex and object-oriented hand behaviors. J. Neurophysiol. 97, 387-406. doi: 10.1152/jn. 00558.2006

Gregoriou, G. G., Gotts, S. J., Zhou, H., and Desimone, R. (2009). High-frequency, long-range coupling between prefrontal and visual cortex during attention. Science 324, 1207-1210. doi: 10.1126/science.1171402

Hadjidimitrakis, K., Bertozzi, F., Breveglieri, R., Bosco, A., Galletti, C., and Fattori, P. (2014a). Common neural substrate for processing depth and direction signals for reaching in the monkey medial posterior parietal cortex. Cereb. Cortex 24, 1645-1657. doi: 10.1093/cercor/bht021
Hadjidimitrakis, K., Bertozzi, F., Breveglieri, R., Fattori, P., and Galletti, C. (2014b). Body-centered, mixed, but not hand-centered coding of visual targets in the medial posterior parietal cortex during reaches in $3 \mathrm{D}$ space. Cereb. Cortex 24 3209-3220. doi: 10.1093/cercor/bht181

Hadjidimitrakis, K., Breveglieri, R., Bosco, A., and Fattori, P. (2012). Threedimensional eye position signals shape both peripersonal space and arm movement activity in the medial posterior parietal cortex. Front. Integr. Neurosci. 6:37. doi: 10.3389/fnint.2012.00037

Hadjidimitrakis, K., Dal Bo', G., Breveglieri, R., Galletti, C., and Fattori, P. (2015). Overlapping representations for reach depth and direction in caudal superior parietal lobule of macaques. J. Neurophysiol. 114, 2340-2352. doi: 10.1152/jn. 00486.2015

Hagan, M. A., Dean, H. L., and Pesaran, B. (2012). Spike-field activity in parietal area LIP during coordinated reach and saccade movements. J. Neurophysiol. 107, 1275-1290. doi: 10.1152/jn.00867.2011

Hauschild, M., Mulliken, G. H., Fineman, I., Loeb, G. E., and Andersen, R. A. (2012). Cognitive signals for brain-machine interfaces in posterior parietal cortex include continuous 3D trajectory commands. Proc. Natl. Acad. Sci. US A 109, 17075-17080. doi: 10.1073/pnas.1215092109

Hawellek, D. J., Wong, Y. T., and Pesaran, B. (2016). Temporal coding of rewardguided choice in the posterior parietal cortex. Proc. Natl. Acad. Sci. U S A 113 , 13492-13497. doi: 10.1073/pnas.1606479113

Hayhoe, M. M., Shrivastava, A., Mruczek, R., and Pelz, J. B. (2003). Visual memory and motor planning in a natural task. J. Vis. 3, 49-63. doi: 10.1167/3.1.6

Heed, T., Leone, F. T., Toni, I., and Medendorp, W. P. (2016). Functional versus effector-specific organization of the human posterior parietal cortex: revisited. J. Neurophysiol. 116, 1885-1899. doi: 10.1152/jn.00312.2014

Heider, B., Karnik, A., Ramalingam, N., and Siegel, R. M. (2010). Neural representation during visually guided reaching in macaque posterior parietal cortex. J. Neurophysiol. 104, 3494-3509. doi: 10.1152/jn.010 50.2009

Hochberg, L. R., Bacher, D., Jarosiewicz, B., Masse, N. Y., Simeral, J. D., Vogel, J., et al. (2012). Reach and grasp by people with tetraplegia using a neurally controlled robotic arm. Nature 485, 372-375. doi: 10.1038/nature 11076

Husain, M., and Nachev, P. (2007). Space and the parietal cortex. Trends Cogn. Sci. 11, 30-36. doi: 10.1016/j.tics.2006.10.011

Hwang, E. J., Hauschild, M., Wilke, M., and Andersen, R. A. (2012). Inactivation of the parietal reach region causes optic ataxia, impairing reaches but not saccades. Neuron 76, 1021-1029. doi: 10.1016/j.neuron.2012.10.030

Jazayeri, M., Lindbloom-Brown, Z., and Horwitz, G. D. (2012). Saccadic eye movements evoked by optogenetic activation of primate V1. Nat. Neurosci. 15, 1368-1370. doi: 10.1038/nn.3210

Jeannerod, M., Arbib, M. A., Rizzolatti, G., and Sakata, H. (1995). Grasping objects: the cortical mechanisms of visuomotor transformation. Trends Neurosci. 18, 314-320. doi: 10.1016/0166-2236(95)93921-j

Johansson, R. S., Westling, G., Bäckström, A., and Flanagan, J. R. (2001). Eye-hand coordination in object manipulation. J. Neurosci. 21, 6917-6932. doi: 10.1523/JNEUROSCI.21-17-06917.2001

Kaas, J. H., and Stepniewska, I. (2016). Evolution of posterior parietal cortex and parietal-frontal networks for specific actions in primates. J. Comp. Neurol. 524, 595-608. doi: 10.1002/cne.23838

Katz, L. N., Yates, J. L., Pillow, J. W., and Huk, A. C. (2016). Dissociated functional significance of decision-related activity in the primate dorsal stream. Nature 535, 285-288. doi: 10.1038/nature18617

Klaes, C., Westendorff, S., Chakrabarti, S., and Gail, A. (2011). Choosing goals, not rules: deciding among rule-based action plans. Neuron 70, 536-548. doi: 10.1016/j.neuron.2011.02.053

Kobayashi, Y., and Amaral, D. G. (2003). Macaque monkey retrosplenial cortex: II. cortical afferents. J. Comp. Neurol. 466, 48-79. doi: 10.1002/cne. 10883

Kravitz, D. J., Saleem, K. S., Baker, C. I., and Mishkin, M. (2011). A new neural framework for visuospatial processing. Nat. Rev. Neurosci. 12, 217-230. doi: $10.1038 / \mathrm{nrn} 3008$

Kutz, D. F., Fattori, P., Gamberini, M., Breveglieri, R., and Galletti, C. (2003). Early- and late-responding cells to saccadic eye movements in the cortical area V6A of macaque monkey. Exp. Brain Res. 149, 83-95. doi: 10.1007/s00221-0021337-9 
Lacquaniti, F., Guigon, E., Bianchi, L., Ferraina, S., and Caminiti, R. (1995). Representing spatial information for limb movement: role of area 5 in the monkey. Cereb. Cortex 5, 391-409. doi: 10.1093/cercor/5.5.391

Land, M. F., and Hayhoe, M. (2001). In what ways do eye movements contribute to everyday activities? Vision Res. 41, 3559-3565. doi: 10.1016/s00426989(01)00102-x

Lehmann, S. J., and Scherberger, H. (2013). Reach and gaze representations in macaque parietal and premotor grasp areas. J. Neurosci. 33, 7038-7049. doi: 10.1523/JNEUROSCI.5568-12.2013

Lewis, J. W., and Van Essen, D. C. (2000). Corticocortical connections of visual, sensorimotor, and multimodal processing area in the parietal lobe of the macaque monkey. J. Comp. Neurol. 428, 112-137. doi: 10.1002/10969861(20001204)428:1<112::aid-cne8>3.0.co;2-9

Li, Y., and Cui, H. (2013). Dorsal parietal area 5 encodes immediate reach in sequential arm movements. J. Neurosci. 33, 14455-14465. doi: 10.1523/JNEUROSCI.1162-13.2013

Marconi, B., Genovesio, A., Battaglia-Mayer, A., Ferraina, S., Squatrito, S., Molinari, M., et al. (2001). Eye-hand coordination during reaching. I. Anatomical relationships between parietal and frontal cortex. Cereb. Cortex 11, 513-527. doi: 10.1093/cercor/11.6.513

Markowitz, D. A., Wong, Y. T., Gray, C. M., and Pesaran, B. (2011). Optimizing the decoding of movement goals from local field potentials in macaque cortex. J. Neurosci. 31, 18412-18422. doi: 10.1523/JNEUROSCI.416511.2011

Marzocchi, N., Breveglieri, R., Galletti, C., and Fattori, P. (2008). Reaching activity in parietal area V6A of macaque: eye influence on arm activity or retinocentric coding of reaching movements? Eur. J. Neurosci. 27, 775-789. doi: 10.1111/j. 1460-9568.2008.06021.x

Matelli, M., and Luppino, G. (2001). Parietofrontal circuits for action and space perception in the macaque monkey. Neuroimage 14, S27-S32. doi: 10.1006/nimg.2001.0835

McGuire, L. M., and Sabes, P. N. (2011). Heterogeneous representations in the superior parietal lobule are common across reaches to visual and proprioceptive targets. J. Neurosci. 31, 6661-6673. doi: 10.1523/jneurosci.292110.2011

Mitzdorf, U. (1985). Current source-density method and application in cat cerebral cortex: investigation of evoked potentials and EEG phenomena. Physiol. Rev. 65, 37-100. doi: 10.1152/physrev.1985.65.1.37

Mountcastle, V. B., Lynch, J. C., Georgopoulos, A., Sakata, H., and Acuna, C. (1975). Posterior parietal association cortex of the monkey: command functions for operations within extrapersonal space. J. Neurophysiol. 38, 871-908. doi: 10.1152/jn.1975.38.4.871

Mullette-Gillman, O. D. A., Cohen, Y. E., and Groh, J. M. (2009). Motorrelated signals in the intraparietal cortex encode locations in a hybrid, rather than eye-centered reference frame. Cereb. Cortex 19, 1761-1775. doi: 10.1093/cercor/bhn207

Mulliken, G. H., Musallam, S., and Andersen, R. A. (2008a). Decoding trajectories from posterior parietal cortex ensembles. J. Neurosci. 28, 12913-12926. doi: 10.1523/jneurosci.1463-08.2008

Mulliken, G. H., Musallam, S., and Andersen, R. A. (2008b). Forward estimation of movement state in posterior parietal cortex. Proc. Natl. Acad. Sci. U S A 105, 8170-8177. doi: 10.1073/pnas.0802602105

Murata, A., Gallese, V., Luppino, G., Kaseda, M., and Sakata, H. (2000). Selectivity for the shape, size and orientation of objects for grasping in neurons of monkey parietal area AIP. J. Neurophysiol. 83, 2580-2601. doi: 10.1152/jn.2000. 83.5.2580

Musallam, S., Corneil, B. D., Greger, B., Scherberger, H., and Andersen, R. A. (2004). Cognitive control signals for neural prosthetics. Science 305, 258-262. doi: 10.1126/science.1097938

Padberg, J., Cooke, D. F., Cerkevich, C. M., Kaas, J. H., and Krubitzer, L. (2019). Cortical connections of area 2 and posterior parietal area 5 in macaque monkeys. J. Comp. Neurol. 527, 718-737. doi: 10.1002/cne.24453

Passarelli, L., Rosa, M. G. P., Bakola, S., Gamberini, M., Worthy, K. H., Fattori, P., et al. (2018). Uniformity and diversity of cortical projections to precuneate areas in the macaque monkey: what defines area PGm? Cereb. Cortex 28, 1700-1717. doi: 10.1093/cercor/bhx067

Passarelli, L., Rosa, M. G. P., Gamberini, M., Bakola, S., Burman, K. J., Fattori, P., et al. (2011). Cortical connections of area V6Av in the macaque: a visual- input node to the eye/hand coordination system. J. Neurosci. 31, 1790-1801. doi: 10.1523/jneurosci.4784-10.2011

Pesaran, B., Pezaris, J. S., Sahani, M., Mitra, P. P., and Andersen, R. A. (2002) Temporal structure in neuronal activity during working memory in macaque parietal cortex. Nat. Neurosci. 5, 805-811. doi: 10.1038/nn890

Piserchia, V., Breveglieri, R., Hadjidimitrakis, K., Bertozzi, F., Galletti, C., and Fattori, P. (2017). Mixed body/hand reference frame for reaching in 3D space in macaque parietal area PEc. Cereb. Cortex 27, 1976-1990. doi: 10.1093/cercor/bhw039

Raos, V., Umiltá, M. A., Gallese, V., and Fogassi, L. (2004). Functional properties of grasping-related neurons in the dorsal premotor area F2 of the macaque monkey. J. Neurophysiol. 92, 1990-2002. doi: 10.1152/jn.00154.2004

Reichenbach, A., Bresciani, J. P., Peer, A., Bülthoff, H. H., and Thielscher, A. (2011). Contributions of the PPC to online control of visually guided reaching movements assessed with fMRI-guided TMS. Cereb. Cortex 21, 1602-1612. doi: $10.1093 /$ cercor/bhq225

Rizzolatti, G., and Matelli, M. (2003). Two different streams form the dorsal visual system: anatomy and functions. Exp. Brain Res. 153, 146-157. doi: 10.1007/s00221-003-1588-0

Rozzi, S., Calzavara, R., Belmalih, A., Borra, E., Gregoriou, G. G., Matelli, M., et al. (2006). Cortical connections of the inferior parietal cortical convexity of the macaque monkey. Cereb. Cortex 16, 1389-1417. doi: 10.1093/cercor/bhj076

Rozzi, S., Ferrari, P. F., Bonini, L., Rizzolatti, G., and Fogassi, L. (2008). Functional organization of inferior parietal lobule convexity in the macaque monkey: electrophysiological characterization of motor, sensory and mirror responses and their correlation with cytoarchitectonic areas. Eur. J. Neurosci. 28, 1569-1588. doi: 10.1111/j.1460-9568.2008.06395.x

Saalmann, Y. B., Pigarev, I. N., and Vidyasagar, T. R. (2007). Neural mechanisms of visual attention: how top-down feedback highlights relevant locations. Science 316, 1612-1615. doi: 10.1126/science.1139140

Savaki, H. E., Gregoriou, G. G., Bakola, S., Raos, V., and Moschovakis, A. K. (2010). The place code of saccade metrics in the lateral bank of the intraparietal sulcus. J. Neurosci. 30, 1118-1127. doi: 10.1523/jneurosci.2268-09.2010

Scherberger, H., Jarvis, M. R., and Andersen, R. A. (2005). Cortical local field potential encodes movement intentions in the posterior parietal cortex. Neuron 46, 347-354. doi: 10.1016/j.neuron.2005.03.004

Seelke, A. M., Padberg, J. J., Disbrow, E., Purnell, S. M., Recanzone, G., and Krubitzer, L. (2012). Topographic maps within Brodmann's area 5 of macaque monkeys. Cereb. Cortex 22, 1834-1850. doi: 10.1093/cercor/ bhr257

Shanechi, M. M., Williams, Z. M., Wornell, G. W., Hu, R. C., Powers, M., and Brown, E. N. (2013a). A real-time brain-machine interface combining motor target and trajectory intent using an optimal feedback control design. PLoS One 8:e59049. doi: 10.1371/journal.pone.0059049

Shanechi, M. M., Wornell, G. W., Williams, Z. M., and Brown, E. N. (2013b). Feedback-controlled parallel point process filter for estimation of goal-directed movements from neural signals. IEEE Trans. Neural Syst. Rehabil. Eng. 21, 129-140. doi: 10.1109/TNSRE.2012.2221743

Snyder, L. H., Batista, A. P., and Andersen, R. A. (1997). Coding of intention in the posterior parietal cortex. Nature 386, 167-170. doi: 10.1038/386167a0

Stark, E., Asher, I., and Abeles, M. (2007). Encoding of reach and grasp by single neurons in premotor cortex is independent of recording site. J. Neurophysiol. 97, 3351-3364. doi: 10.1152/jn.01328.2006

Tanné-Gariépy, J., Rouiller, E. M., and Boussaoud, D. (2002). Parietal inputs to dorsal versus ventral premotor areas in the macaque monkey: evidence for largely segregated visuomotor pathways. Exp. Brain Res. 145, 91-103. doi: 10.1007/s00221-002-1078-9

Vann, S. D., Aggleton, J. P., and Maguire, E. A. (2009). What does the retrosplenial cortex do? Nat. Rev. Neurosci. 10, 792-802. doi: 10.1038/nrn2733

Vesia, M., and Crawford, J. D. (2012). Specialization of reach function in human posterior parietal cortex. Exp. Brain Res. 221, 1-18. doi: 10.1007/s00221-0123158-9

Watakabe, A., Sadakane, O., Hata, K., Ohtsuka, M., Takaji, M., and Yamamori, T. (2016). Application of viral vectors to the study of neural connectivities and neural circuits in the marmoset brain. Dev. Neurobiol. 77, 354-372. doi: 10.1002/dneu.22459

Wessberg, J., Stambaugh, C. R., Kralik, J. D., Beck, P. D., Laubach, M., Chapin, J. K., et al. (2000). Real-time prediction of hand trajectory by ensembles 
of cortical neurons in primates. Nature 408, 361-365. doi: 10.1038/350 42582

Wilke, M., Kagan, I., and Andersen, R. A. (2012). Functional imaging reveals rapid reorganization of cortical activity after parietal inactivation in monkeys. Proc. Natl. Acad. Sci. U S A 109, 8274-8279. doi: 10.1073/pnas.120 4789109

Wong, Y. T., Fabiszak, M. M., Novikov, Y., Daw, N. D., and Pesaran, B. (2016). Coherent neuronal ensembles are rapidly recruited when making a look-reach decision. Nat. Neurosci. 19, 327-334. doi: 10.1038/nn.4210

Yttri, E. A., Wang, C., Liu, Y., and Snyder, L. H. (2014). The parietal reach region is limb specific and not involved in eye-hand coordination. J. Neurophysiol. 111, 520-532. doi: 10.1152/jn.00058.2013

Yu, H. H., Chaplin, T. A., Davies, A. J., Verma, R., and Rosa, M. G. P. (2012). A specialized area in limbic cortex for fast analysis of peripheral vision. Curr. Biol. 22, 1351-1357. doi: 10.1016/j.cub.2012.05.029
Zhang, C. Y., Aflalo, T., Revechkis, B., Rosario, E. R., Ouellette, D., Pouratian, N., et al. (2017). Partially mixed selectivity in human posterior parietal association cortex. Neuron 95, 697.e4-708.e4. doi: 10.1016/j.neuron.2017.06.040

Conflict of Interest Statement: The authors declare that the research was conducted in the absence of any commercial or financial relationships that could be construed as a potential conflict of interest.

Copyright (C) 2019 Hadjidimitrakis, Bakola, Wong and Hagan. This is an open-access article distributed under the terms of the Creative Commons Attribution License (CC BY). The use, distribution or reproduction in other forums is permitted, provided the original author(s) and the copyright owner(s) are credited and that the original publication in this journal is cited, in accordance with accepted academic practice. No use, distribution or reproduction is permitted which does not comply with these terms. 